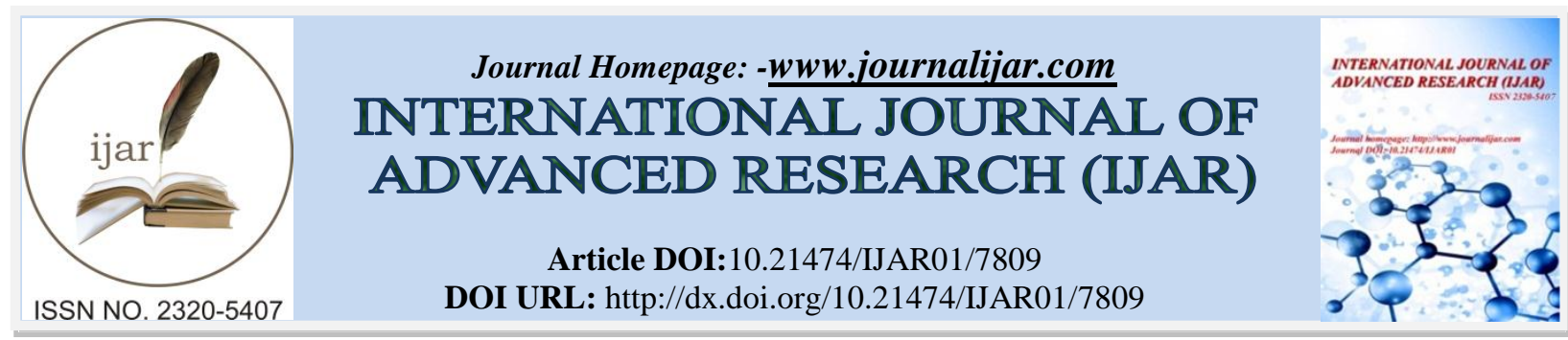

RESEARCH ARTICLE

\title{
MATERNAL OBESITY AND FACTORS ASSOCIATED WITH MODE OF DELIVERY.
}

\author{
Khawla Ali Majeed ${ }^{1}$, Abbas A. J. AL - Salihi ${ }^{2}$, and Khulood Abdul Wahab Jumaah ${ }^{3}$. \\ 1. Ministry of Health - Baghdad Medical office - Al-Karkh, Al - Dorah District - Al-Seha Primary Health Center, \\ Baghdad, IRAQ. \\ 2. High Institute of Infertility Diagnosis and ART's, AL-Nahrain University, Baghdad, IRAQ. \\ 3. Ministry of Health - Baghdad Medical office - Al-Karkh, - Karkh Maternity Hospital, Baghdad, IRAQ.
}

\section{Manuscript Info}

Manuscript History

Received: 5 August 2018

Final Accepted: 7 September 2018

Published: October 2018

Keywords: -

Obesity, Cesarean Section, Baghdad.

\section{Abstract}

Background: Maternal obesity has become one of the most commonly occurring risk factors in obstetric practice. Obesity during pregnancy and pre-pregnancy increases the risk of various pregnancy complications, like high blood pressure, gestational diabetes, preterm labor, stillbirthand maternal mortality. The objectiveofan identified factor associated with maternal obesity.

Methods: A cross-sectional study of 340 pregnant women performed from the obstetric hospital in Baghdad, Iraq, between $1^{\text {st }}$ jun to 30 December 2016. Data collection by Questionnaires were completed through interviews with pregnant women and using patient records. To analyze the data, the Chi-square test was run, using SPSSversion 20.

Results: The prevalence of maternal obesity was $57.8 \%$ With mean body mass index (BMI) was $26.6 \pm 8.52 \mathrm{Kg} / \mathrm{m} 2$ and it was significantly higher among women who delivered by cesarean section. The significantly high rate of maternal obesity was found in low education women, havethe previous history of abortion and more age women.

Conclusion: Obese women with a higher risk of having a CS.

Copy Right, IJAR, 2018,. All rights reserved.

\section{Introduction: -}

Maternal obesity has become one of the most commonly occurring risk factors in obstetric practice. Obesity is defined as having an excessive amount of body fat. A measurement based on height and weight called the body mass index (BMI). Therefore, increase body mass index (BMI) $30 \mathrm{~kg} / \mathrm{m}^{2}$ or more to any women at the first antenatal consultation may be considered as obese women.

Body mass index (BMI) is the index that measures body weight versus its length and is calculated by dividing the person's weight in kilograms per square meter in length $(\mathrm{kg} / \mathrm{m} 2){ }^{(1)}$

obesity can be classification into three types according to the relationship between BMI with morbidity and mortality ${ }^{(2)}$

1. BMI 30.0-34.9 (Class I)

2. BMI 35.0-39.9 (Class 2)

3. BMI 40 and over (Class 3 or morbid obesity)

Obesity has a dramatic impact on pregnancy outcome. Apart from an associated increased prevalence of diabetes and hypertension, obesity in pregnancy has been associated with poor perinatal and neonatal outcomes. Obese 
mothers have an increased risk of pregnancy complications such as anemia, hypertension, pre-eclampsia, preterm delivery, emergency cesarean section, and gestational diabetes. ${ }^{(3)}$

Demonstrated that obesity significantly increases the rate of cesarean section and there is little evidence in the literature about whether an elective cesarean section or normal vaginal birth is the optimal mode of delivery in the morbidly obese parturient. ${ }^{(4)}$

It is well-documented that surgery in the morbidly obese patient poses many surgical, anesthetic, and logistical difficulties. Moreover, patients with BMI $>40 \mathrm{~kg} / \mathrm{m}^{2}$ have an increase in total operative time and time from skin incision to delivery. ${ }^{(4)}$

\section{Weight gain during pregnancy:}

The amount of weight you gain during pregnancy is important for the health of your pregnancy and for the longterm health of you and your baby, how much weight you should gain during pregnancy is based on your body mass index (BMI) before pregnancy. In the first trimester (first 12 weeks), most women do not need to gain much weight (usually less than $2 \mathrm{~kg}$ ) - which is just as well for those who have morning sickness early in pregnancy. Some women lose a small amount of weight. In the first months, and then begin to gain weight steadily in the second and third trimester of pregnancy. (5) Weight gain in women is not much during the first three months of pregnancy (between half and $2 \mathrm{~kg}$ ). The increase also varies from month to month.

\begin{tabular}{|c|c|}
\hline pre-pregnancy or early pregnancy (less than 10 weeks) BMI $\left(\mathbf{k g} / \mathbf{m}^{2}\right)$ & Total weight gain range \\
\hline Underweight $(<18.5)$ & $12.5 \mathrm{~kg}-18 \mathrm{~kg}$ \\
\hline Healthy weight $(18.5-24.9)$ & $11.5 \mathrm{~kg}-16 \mathrm{~kg}$ \\
\hline Overweight $(25.0-29.9)$ & $7 \mathrm{~kg}-11.5 \mathrm{~kg}$ \\
\hline Obese $(\geq 30.0)$ & $5 \mathrm{~kg}-9 \mathrm{~kg}$ \\
\hline
\end{tabular}

\section{High levels of obesity and high cesarean delivery rates}

With high levels of obesity in adults, there was a related increase in maternal obesity. A Scottish study found that the prevalence of obesity increased from $9.4 \%$ to $18.9 \%$ over a period of 12 years. In other studies, in Britain and Ireland, nearly one-fifth of women who were booked for prenatal care were obese. The severity of obesity is also increasing. Based on the WHO sub-classification of obesity, a recent national review of pregnant women in the United Kingdom found that 5 percent was category 2, moderate obesity, 2.0 percent classified as Category 3, or severe obesity. ${ }^{(8)}$

Rising levels of obesity in women of child-bearing age and gestational weight gain have been reported which has implications for the woman's lifelong health as well as for the pregnancy itself ${ }^{(9)}$. The publication of the United States Institute of Medicine (IOM) has published new guidelines for weight gain during pregnancy based on WHO baseline criteria for body mass index (BMI) indicators with a relatively specific set of recommended gains for obese mothers, from $5.0-9.0 \mathrm{~kg}$.

Numerous studies have reported an association between maternal obesity and an increased CS rate ${ }^{(10)}$. There have been three recent meta-analyses which studied the issue of obesity and cesarean section. In the 2007 analysis, the risk of CS overall was increased by 2.05 in obese women, and 2.89 in morbidly obese women ${ }^{(11)}$. The 2008 metaanalysis found that the overall CS was twice as high in the obese BMI category compared with the ideal BMI ${ }^{(12)}$. In the 2009 systematic review and meta-analysis of 11 cohort studies, the risk of CS was increased by 2.26 in obese women and by 3.38 in morbidly obese women compared with women with a normal BMI ${ }^{(13)}$. a study in the first trimester found that maternal obesity, based on an accurate calculation of BMI, was associated with an increase in emergency CS in primigravidas and an increase in elective CS in multigravidas ${ }^{(14)}$. increase in emergency CS in obese primigravidas was associated with induction of labor and a high rate of CS for fetal distress. While the increase in elective CS in multigravidas was associated with a high rate of repeat elective CS.

the prevalence of obesity in Iraq, according to the Ministry of Health, among women of childbearing age was 38.2\% in 2006. ${ }^{(14)}$ Moreover, in Baghdad between 1997 and 2007 the prevalence of obesity among women in reproductive age increased from 23.6 to $25 \%$. $^{(15)}$ 
Globally the prevalence of maternal obesity has alsoincreased, rising from $9-10 \%$ in the early 1990 's to $16-19 \%$ in the year 2000. ${ }^{(16)}$

Obesity during pregnancy and prepregnancy increases the risk of various pregnancy complications, including:

Abortion:

The most obese women are at increased risk of pregnancy loss (abortion) compared to women of normal weight. A number of studies report a significantly higher incidence of early and recurrent early miscarriages amongst 'obese' women compared with women in the 'normal weight'. (17)

\section{Birth defects:}

More medical research suggests that obese women with children are more likely to have congenital defects, such as heart defects and neural tube defects such as anencephaly and spina bifida; cardiovascular anomalies; anomalies of the intestinal tract; congenital hernia; orofacial clefts; eye anomalies; genital anomalies including hypospadias; limb anomalies; and multiple congenital anomalies of the central nervous system. A population-based study of 10,249 cases by Waller et al, as cited in, Phatak and Ramsay (2010, p. 447) concluded that 'pre-pregnancy maternal obesity was positively associated with 7 out of 16 categories of birth defects. ${ }^{(18)}$

\section{Diagnostic difficulty:}

The accumulation of fat in the pregnant mother's body may make it difficult to see some problems with the dissection of the child an ultrasound exam. Checking the baby's heart rate during labor also may be more difficult if you are obese. ${ }^{(19)}$

\section{Macrosomia:}

Increase the size of the child is greater than normal. May cause the risk of injury to the child during childbirth. For example, the child's shoulder can be attached during delivery. macrosomia also increases the risk of cesarean delivery. Infants born with too much body fat have a greater chance of being obese later in life. ${ }^{(20)}$

\section{Premature birth:}

Obesity of the pregnant mother may lead to problems, such as pre-eclampsia, to the birth of prematurely diagnosed Jadeja. This means that the child is delivered early for medical reasons. Preterm infants are not as sophisticated as infants born after 39 weeks of pregnancy. As a result, they have an increased risk of short- and long-term health problems. ${ }^{(21)}$

\section{Fertility:}

A number of studies in the review considered 'maternal obesity' to be associated with sub-fertility, toimpede the success of fertility treatment and be associated with the increased incidence of the polycysticovarian syndrome ${ }^{(\mathbf{1 8})}$

\section{Stillbirth:}

Researchers also acknowledge that the underlying mechanism associating obesity and stillbirth is unknown, obesity increases the risk of stillbirth are likely to be multifactorial', and may include the altered metabolism profiles of 'obese' women, the association of metabolic disorders including diabetes and pre-eclampsia with obesity, the nutritional status of obese women, altered perception of fetal movements, and much higher rates of sleep-related disorders in 'obese' pregnant that placental dysfunction may be the probable underlying mechanism.. ${ }^{(22)}$

\section{Hypertensive disorders:}

including pre-eclampsia, complicate $2-10 \%$ of all pregnancies and obesity is a reported risk factor. A systematic overview of 13 cohort studies reported that the risk of pre-eclampsia doubles with each $5-7 \mathrm{~kg} / \mathrm{m} 2$ increase in BMI. In a more recent meta-analysis of 36 studies with nearly 1.7 million subjects, BMI was a weak predictor of preeclampsia However, the accurate measurement of blood pressure is important and in obese subjects. ${ }^{(23)}$

\section{Gestational diabetes:}

The incidence of GDM in pregnancy in women who are obese is higher than that of the general obstetric population. The extent of the increase varies from population to population). ${ }^{(24)}$ 


\section{A difficult vaginal delivery:}

Obese women are more likely to be delivered by cesarean section than women in the normal BMI category. The CD rate had been increasing steadily in recent years, compared to vaginal deliveries, CDs are associated with higher maternal morbidity and mortality and can lead to significant complications in future pregnancies. ${ }^{(25)}$ Obesity conferred a 2-3-fold increased risk of delivery by emergency cesarean section for both primigravidas and multigravidas. In a 2007 meta-analysis of 33 studies, the unadjusted odds ratio (OR) of a cesarean delivery were 1.46 (CI 1.34-1.60), 2.05 (CI 1.86-2.27) and 2.89 (CI 2.28-3.79) among overweight, obese and severely obese women respectively compared with normal weight women. ${ }^{(11)}$ Cesarean delivery may cause complications in future pregnancies, such as recurrent cesarean delivery, or abnormal placenta, pre-pregnancy weight gain and high body mass index may indicate the risk of maternal health and your child's health. Most studies indicate how much weight you need to gain during pregnancy, by working and collaborating with your health care provider to determine what is best in your situation and manage your weight throughout the pregnancy. Start by considering these general guidelines for pregnancy weight gain and obesity. ${ }^{(26)}$

\section{Practical implications related to cesarean section in a morbidly obese patient: Abdominal Incision}

The abdominal incisions used for a cesarean section are usually the focus of discussion and may include the vertical midline incision, Maryland incision, Cohen incision, and Pfannenstiel incision. ${ }^{(27)}$ Modern women tend to be more aware of their body image and the use of the Pfannenstiel incision or low transverse skin incision has become the norm. In morbidly obese patients, however, the use of such an incision in the moist region below the panniculus remains a debated issue. ${ }^{(28)}$ Some support the use of a Pfannenstiel incision in obese patients with a large panniculus, and contradict the classical teaching and concerns that a transverse abdominal incision made under the panniculus fold with a warm moist anaerobic environment would increase bacterial content, leading to a proliferation of numerous microorganisms, producing a bacterial cesspool and promoting infection. ${ }^{(29)}$. Cephalad retraction of the panniculus in morbidly obese patients during cesarean section carries the risk of hypotension and fetal compromise, as well as respiratory difficulties, especially with a regional block, and hence, must be done with great care and concern. ${ }^{(30)}$ The overhanging panniculus is dealt with by some obstetricians by using Montgomery straps applied to the upper abdomen, tied to the operative bed rail to retract the panniculus cephalad, use of hooks to attach a chain to railings across the operating table and a large Doyen's retractor to contain the edge of the panniculus has been described as a simple, effective, and a more convenient alterna. ${ }^{(31)}$

\section{Maternal mortality}

Obesity, in general, is considered a major risk factor for chronic disease including diabetes and hypertension, all of which could by itself contribute to mortality. In a report of British Confidential Enquiry into Maternal Deaths of 391 cases, assessed for a period of three years, from 2000 to 2002, the observations made were that depression and obesity were the major causes of maternal deaths in the UK ${ }^{(32)}$ About $35 \%$ of the deceased women were obese, which was 50\% more than in the general population. Obesity, in general, is considered a major risk factor for health problems and is causally related to chronic diseases, which all contribute to the mortality. ${ }^{(33)}$

\section{Postpartum complications}

In morbidly obese patients the incidence of endometritis is almost three times higher than in non-obese patients, the incidence of postoperative endometritis is even higher at $32.6 \%$ versus $4.9 \%$ in normal-weight women. ${ }^{(34)}$

The incidence of wound infection is more than double in obese patients. Post-cesarean wound infection was found to double with every five-unit increment of BMI, the risk of postoperative infection can be reduced by prophylactic antibiotics ${ }^{(28)}$. The incidence of postpartum hemorrhage varies from no increase to a $70 \%$ increase in morbidly obese women, higher BMI is nevertheless strongly correlated with postpartum anemia ${ }^{(35)}$.

Thromboembolic disease is also more frequent in obese women. However, pulmonary embolism has not been seen to be increased in obese women, as no study has shown a large enough sample, leading to inadequate statistical power, for reliably detecting differences in the rate of this complication. When prophylactic anticoagulants are given, the dose must be related to the woman's body weight. This can be achieved by giving low molecular weight heparin once a day $\cdot{ }^{(36)}$

Postpartum urinary complaints such as stress incontinence are more frequent among obese women, but they are also related to parity and mode of delivery. Postoperative urinary tract infection is also more frequent in obese women. 
Consequently, the hospital stay of obese women is longer than normal weight women after both vaginal and cesarean delivery. ${ }^{(37)}$

\section{Vaginal Birth After Caesarean Section}

In the absence of contraindications, women who have had their first child by Caesarean section are asked to consider vaginal birth in subsequent pregnancies. The success of vaginal birth after Caesarean section is commonly quoted at $80 \% .48$ Obese women are less likely than their lean peers to be successful in delivering vaginally after previous Caesarean section. In women with a BMI > $29 \mathrm{~kg} / \mathrm{m} 2$, the success rate is $54 \%$ to $68 \%$. ${ }^{(38)}$

\section{The Management of Women with Obesity during Pregnancy (High BMI $\geq 30 \mathrm{~kg} / \mathrm{m} 2$ )}

1. All women who are planning pregnancy should have accurate height and weight measurement and BMI calculation. They should be encouraged to maintain BMI in the range of $20 \mathrm{kgm} 2$ to $25 \mathrm{~kg} / \mathrm{m} 2$. Women with a $\mathrm{BMI} \geq 30 \mathrm{~kg} / \mathrm{m} 2$ should be advised to weight before conception to reduce pregnancy complications.

2. The woman should be encouraged to adopt healthy lifestyle practices by improving diet quality and physical activity patterns.

3. Women should be offered referral to a nutritionist or dietician in cases where clinicians lack the knowledge and/or time to provide adequate advice.

4. Consideration should be given to screening for type 2 diabetes prior to conception.

5. Women with a BMI $\geq 30 \mathrm{~kg} / \mathrm{m} 2$ wishing to become pregnant should be advised to take $5 \mathrm{mg}$ folic acid supplementation daily, starting at least one month before conception and continuing during the first trimester of pregnancy.

\section{Methodology: -}

\section{Study Design:}

A cross-sectional study will be used in Baghdad province. Baghdad is the capital of Iraq and divided into two part (Ankara side, and asafe side)

\section{Study Setting:}

A total of 1 hospital will be selected randomly from the 3 hospitals have gynecology and obstetrics department in the Ankara side of Baghdad city

\section{Study Population:}

The target population will be defined as:

1. All pregnant women attendees with the age of 18 years or more who had labor pain for delivery with induced or spontaneous labor was collected.

2. Inclusion criteria were women who had a normal pregnancy (no disease) at 37 weeks of gestation. Primigravida and multigravida were included with natural pregnancy and single live vertical embryos. Pregnant women with the elective cesarean section, asthma, hypertension, and diabetes were excluded. In addition, multiple gestations, and abnormal lie fetus at the time of labor were also excluded

\section{Sample Size:}

For client satisfaction, the minimum sample size for the study was calculated using the Epi-Info statistical software. The sample size is based on the following assumptions: the overall satisfaction is $50 \%$, the confidence level at $95 \%$, the power of the study to be taken at the high level of $90 \%$ for more precision and the $\mathrm{P}$ value of equal or $<0.05$ as a cut point for significance. This gave an estimated sample size of 332 women, which was approximated to 340 women. An extra $10 \%$ of the estimated sample size was added for incomplete or unreliable answers and to reduce sample bias, giving a final sample size of 340 pregnant women, selected a convenience sample.

\section{Sampling Method:}

A multistage sampling technique will be adopted starting with the 3 hospitals in Ankara side of Baghdad city as a first stage, we will choose ( 2 in the city center and 1 in the rural areas). In the second stage and by using a simple random sampling, we will select 1 hospital from each of the 3 hospitals to ensure a representative sample. 


\section{Tools of the study:}

Two modified forms of a questionnaire that draw from WHO/MOH. Exit interview questionnaire by using the Arabic language consists of two components, one of the socio-demographic characteristics and the other component of maternal measuring.

Time Data Collection: -

The study was carried out during the period from the first of junto $15^{\text {th }}$ of December, 2015

\section{Data Collection:}

This study will be carried out by direct interview with the participants using a structured questionnaire. A structured questionnaire is developed to collect information from the pregnant women or accompanier. The subtending was conducted by the researcher. Some information on maternal factors and certain other information was obtained from the records, while other information was obtained from the participant.

\section{Data Collection Tool Questionnaire:}

A structured questionnaire is the base for data collection developed by the researcher and reviewed by the supervisor and it is consisting of;

The demographic information includes: code NO., gender, birthday, weight, height and BMI, age of women in pregnancy, weight of child at birth (low, average, large), and mode of delivery (vaginal or cesarean), Parity was considered as number of gestations resulting in live birth or stillbirth.

Maternal characteristics such as education was coded as not education, and, or primary or secondary education and high education' mother occupation, maternal smoking during pregnancy, weight pre-pregnancy, and family history of diabetes mellitus (DM)/hypertension, Mother's age during delivery, history of abortion and presence of gestational diabetes mellitus were obtained from the pregnancy chart. BMI before pregnancy was classified into two groups as obese ( $\geq 30 \mathrm{~km}-2)$. Maternal age was categorized into three groups such as, $<18,18-34$ and $\geq 35$ years

\section{Anthropometric measurements:}

1. Weight: taken by a sensitive digital UNICEF Scale, with the patients wearing the lightest possible clothes results were taken to the nearest $0.1 \mathrm{~kg}$.

2. height: will be measured by using a measuring without shoes, results were taken to the nearest $0.1 \mathrm{~cm}$.

3. Body mass index (BMI) percentile, was determined using the 2000Centers for Disease Control and Prevention (CDC). BMI is a ratio between height and weight and is calculated by dividing weight in kg by height 2 in $\mathrm{m} 2$ $(\mathrm{BMI}=\mathrm{kg} / \mathrm{m} 2)$.

\section{Data Management Plan:}

\section{Statistical Analysis:}

Data was translated into a computerized database structure. Statistical analyses were done using SPSS (Statistical Package for Social Sciences). Version 20 computer software for windows. Categorical variables were presented as frequency and percentage, Chi-square was used to test the significance of the association between categorical variables. with considered $P$. Value of $\leq 0.05$ was statistically significant.

\section{Ethical consideration:}

1. Agreement of MOH-Iraq, and Baghdad Al Karkh directorate of health

2. The collection of data was kept confidential and not be divulged except for the purpose of the study.

3. The Participant's agreement will be considered and they will be informed that the participation is voluntary and they can withdraw from the study after having agreed to participate.

\section{Results: -}

A total of 340 pregnant women were included in this study, taken from Ankaraobstetric hospital in Baghdad city. The prevalence of overweight and obese women in the study sample was 57\%, consist of $31 \%$ overweight and of those at risk of obesity was $26 \%$ while women were normal weight $40 \%$. as shown in figure (1). 
The highest proportion of pregnant women studied aged were 18-35 years (63\%), and lower proportion age was $>35$ years $(13 \%)$ while the age of pregnant sample less than 18 years $(24 \%)$. the mean age of the studied sample was $(26.7+4.8)$ without any significant associated between age and mode of delivery, but the result showed there was a significant association between age of pregnant women and maternal obesity ,the number of obese women mere than double in older age $(\mathrm{p}=0.01)$. figure $(2)$.

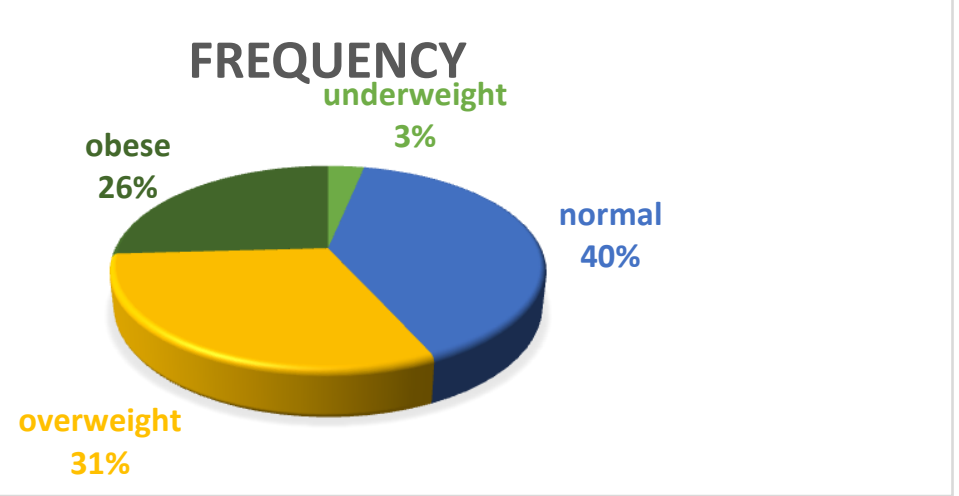

Figure 1: - Distribution of study sample according to nutritional status

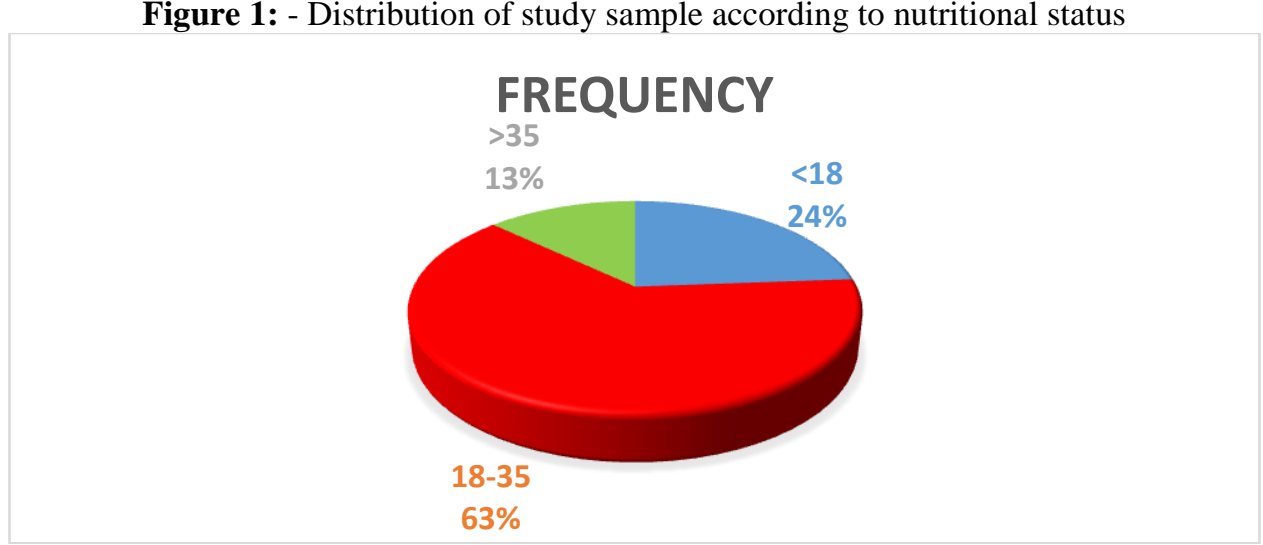

Figure 2: -distribution of studied sample according to age

Regarding to Educational level of women, the study showed that most of the women were at university level (40.9\%), while less than $20 \%$ of illiterate women, with a significant association between the level of education and mode of delivery, this result revealed that mode of delivery (cesarean section) was significantly increased ( $p<0.001)$ with low maternal education. The study also showed a significant associated withthe level of education and maternal obesity, where uneducated women were found to be more overweight than educated women $(\mathrm{p}=0.002)$. Table 2,3

In regard to maternal occupation, only $130(38.2 \%)$ of the sample included in this study were working, while the majority of women $210(61.8 \%)$ were not working (unemployed). with significantly associated with employed women with the mode of delivery (cesarean section), $(\mathrm{p}<0.001)$, while there wasnoa significant association between employed women and maternal obesity $(\mathrm{p}=0.432)$. Table 2,3 


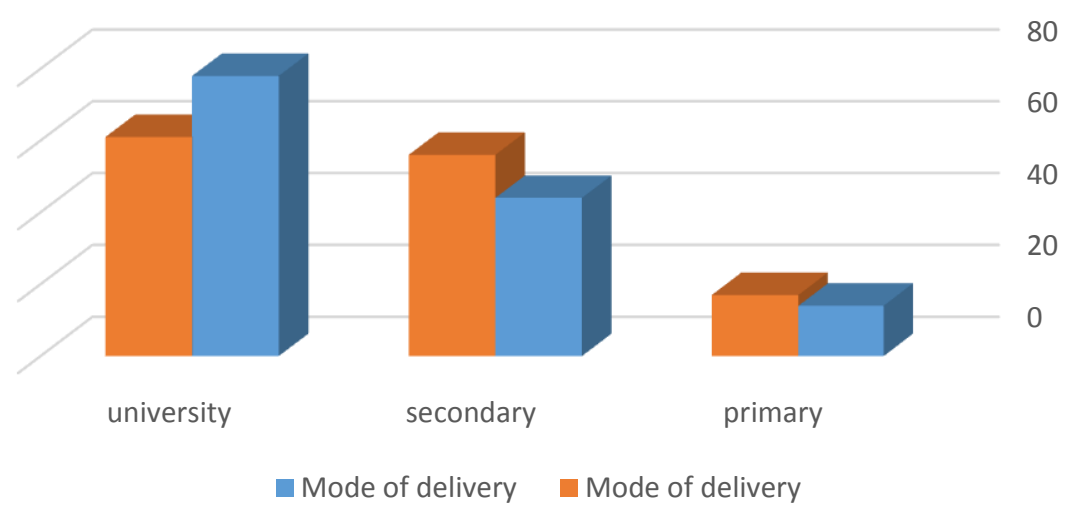

Figure 3: -distribution of studied sample according to mode of delivery and education level.

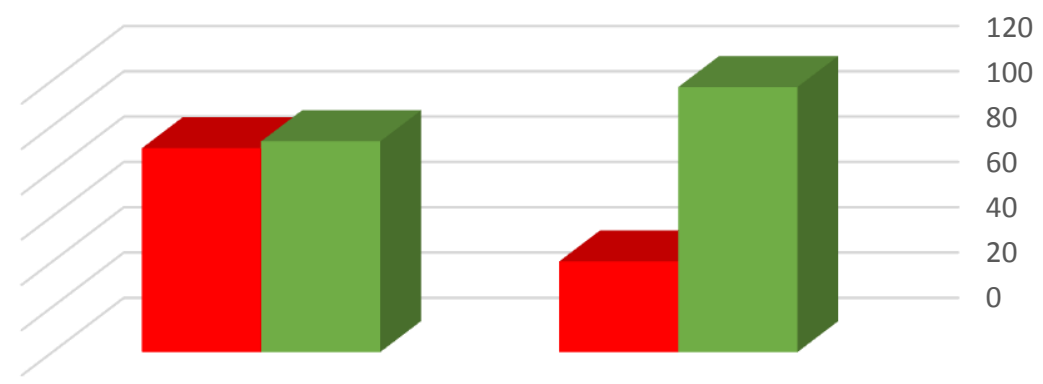

cesarean normal

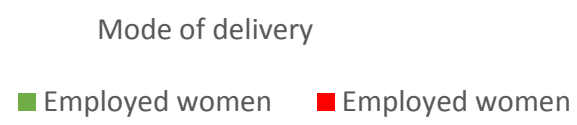

Figure 4: -distribution of studied sample according tothe mode of delivery and occupation.

as well the weight of women before the pregnancy $255(75 \%)$ from total sample were normal weight and $85(25 \%)$ were overweight, but founded significantly associated $(\mathrm{p}<0.007)$ between overweight and obesity women and the cesarean section as compared to normal weight. Table 3

Concerning the Maternal smoking the study result showed the majority of sample nonsmoking 338(99.4) without any significant association with mode of delivery or maternal obesity. Table 3

As well the study founded 134(39.4\%) prim gravida and 206(60.6\%) multigravida but the results did not show any relation between parity and mode of delivery $(\mathrm{p}=0.445)$. while there was a significant association between multigravida and maternal obesity. Table 3,2

Also, the weight of pre-pregnancy women in the total sample was $255(75 \%)$ of normal weight and $85(25 \%)$ were overweight. The results showed a significant increase $(\mathrm{P}<0.007)$ between overweight and obesity in women and cesarean section compared to normal weight. Table 3

Regarding maternal smoking, the results of the study showed that the majority of the non-smokeless sample was 338 (99.4) and there was no correlation between the method of birth or maternal obesity. Table 3

The study also found 134 (39.4\%) primary gravida and $206(60.6 \%)$ multigravida but the results showed no association between parity and birth method $(\mathrm{p}=0.445)$. At the same time, there was a significant correlation between multiple obesity and maternal obesity. Table 3,2 
Table 1: - Distribution of selected sociodemographicvariables among studied women.

$\mathbf{N}=\mathbf{3 4 0}$

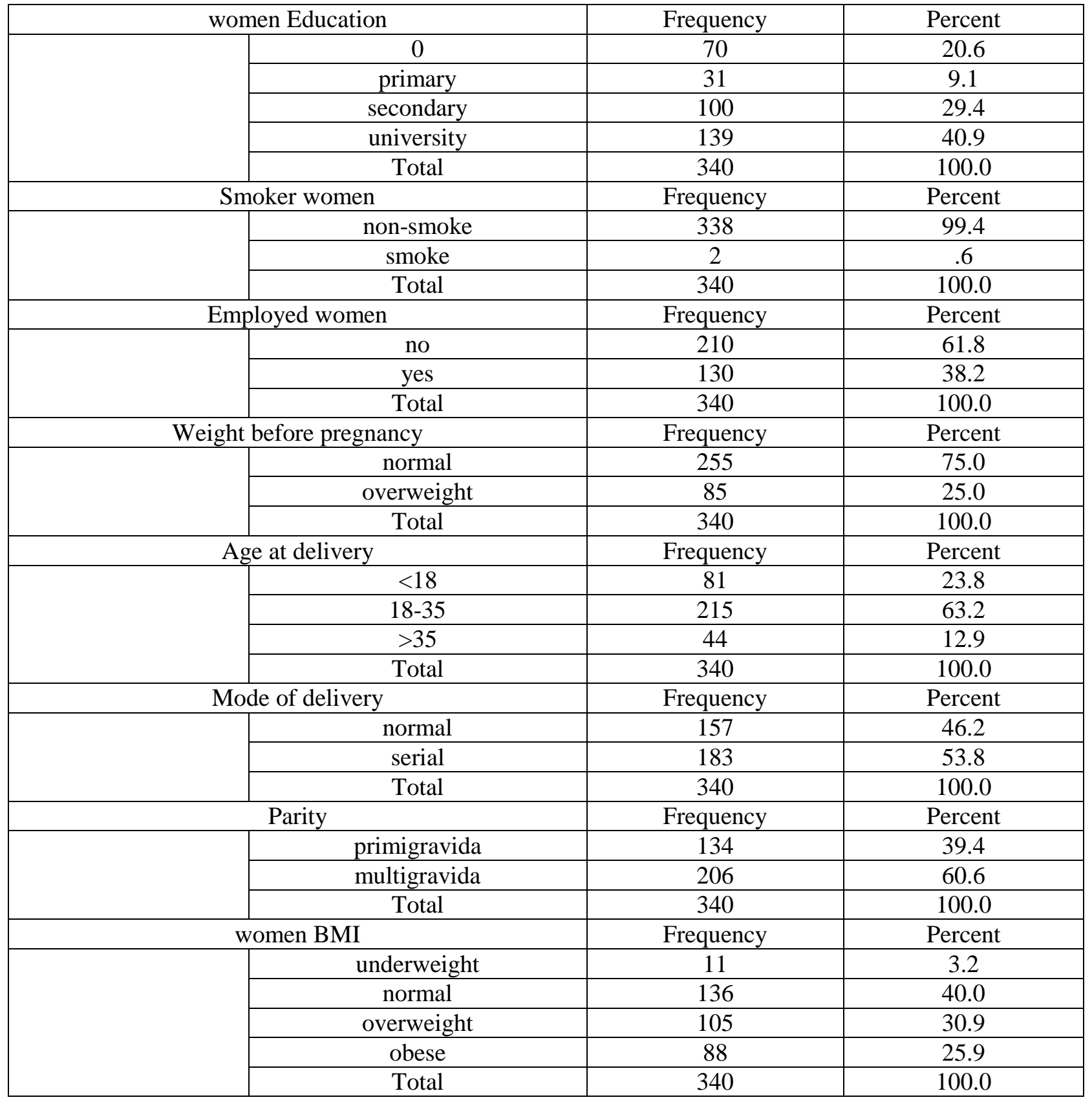

Table 2: - Distribution of studied sample according tothe mode of delivery and maternal characteristic. $\mathrm{n}=340$

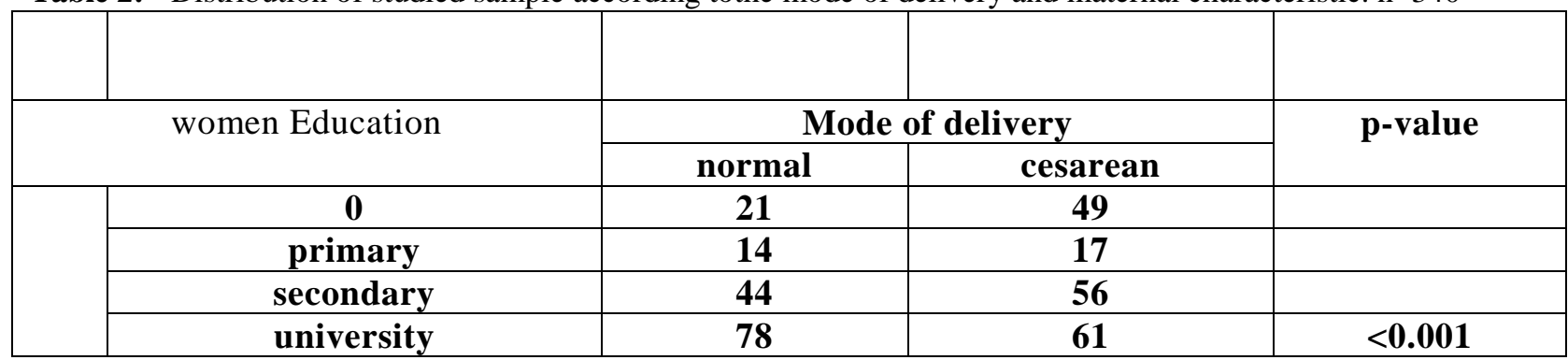




\begin{tabular}{|c|c|c|c|}
\hline Total & 157 & 183 & \\
\hline \multirow{2}{*}{ Smoker women } & \multicolumn{2}{|c|}{ Mode of delivery } & \\
\hline & normal & cesarean & \\
\hline non-smoke & 155 & 183 & \\
\hline smoke & 2 & $\mathbf{0}$ & 0.212 \\
\hline Total & 157 & 183 & \\
\hline \multirow[t]{2}{*}{ Employed women } & \multicolumn{2}{|c|}{ Mode of delivery } & \\
\hline & normal & cesarean & \\
\hline no & 117 & 93 & \\
\hline yes & 40 & 90 & $<0.001$ \\
\hline Total & 157 & 183 & \\
\hline \multirow{2}{*}{ Weight before pregnancy } & \multicolumn{2}{|c|}{ Mode of delivery } & \\
\hline & normal & cesarean & \\
\hline normal & 128 & 127 & \\
\hline overweight & 29 & 56 & $\mathbf{0 . 0 0 7}$ \\
\hline Total & 157 & 183 & \\
\hline \multirow[t]{2}{*}{ Age at delivery } & \multicolumn{2}{|c|}{ Mode of delivery } & \\
\hline & normal & cesarean & \\
\hline$<18$ & 38 & 43 & \\
\hline 18-35 & 99 & 116 & 0.868 \\
\hline$>35$ & 20 & 24 & \\
\hline Total & 157 & 183 & \\
\hline \multirow[t]{2}{*}{ Parity } & \multicolumn{2}{|c|}{ Mode of delivery } & \\
\hline & normal & cesarean & \\
\hline primigravida & 63 & 71 & \\
\hline multigravida & 94 & 112 & 0.445 \\
\hline Total & 157 & 183 & \\
\hline
\end{tabular}

Table 3: - Distribution of studied sample according to maternal obesity and maternal characteristic. $\mathrm{n}=340$

\begin{tabular}{|c|c|c|c|}
\hline women Education & \multicolumn{2}{|c|}{ maternal BMI } & \multirow[t]{2}{*}{ p-value } \\
\hline $\mathbf{0}$ & 20 & 50 & \\
\hline primary & 12 & 19 & \\
\hline secondary & 44 & 56 & $<0.002$ \\
\hline university & 71 & 68 & \\
\hline Total & 147 & 193 & \\
\hline \multicolumn{3}{|l|}{ Employed women } & \\
\hline no & 92 & 118 & \\
\hline yes & 55 & 75 & 0.437 \\
\hline Total & 147 & 193 & \\
\hline \multicolumn{3}{|l|}{ Smoker women } & \\
\hline non-smoke & 147 & 191 & \\
\hline smoke & $\mathbf{0}$ & 2 & 0.321 \\
\hline Total & 147 & 193 & \\
\hline Age at delivery & & & \\
\hline
\end{tabular}




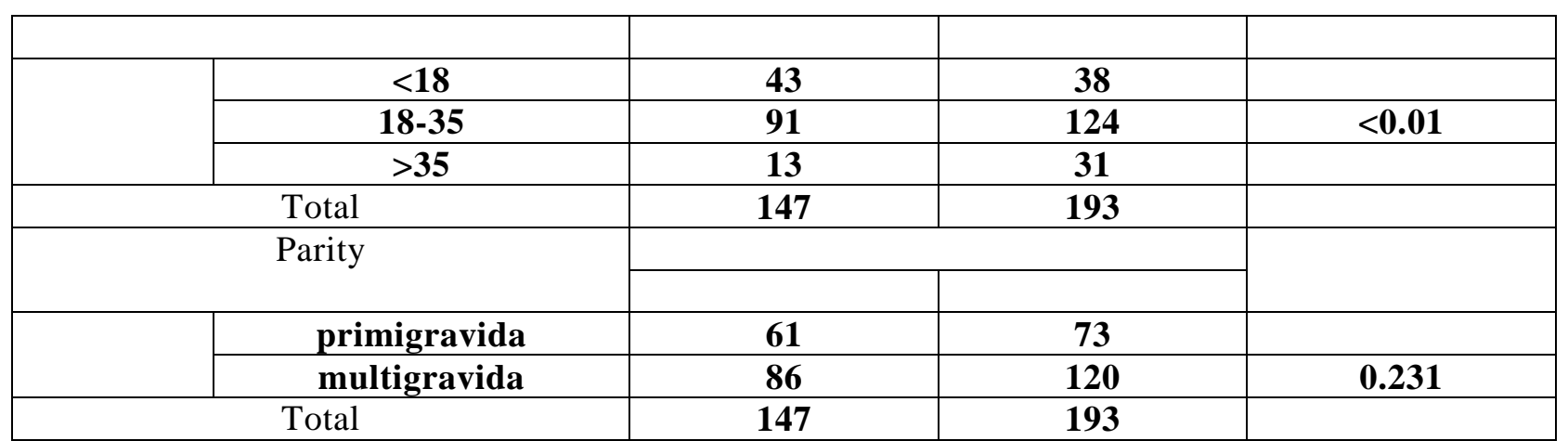

The current study showed that the average body mass index was (27.20) with stander deviation (5.23), there was a significant association between obese women and the cesarean section, where the results showed that obese women were more exposed to cesarean sections than normal births.

(table 4).

Regarding abortion the current study founded the women that have a history of abortion were more than double in obese women $(\mathrm{n}=141)$, with a significant association between maternal obesity and history of abortion $(\mathrm{p}=0.05)$. table 4.

Table 4:-Maternal BMI related to the history of abortion and mode of delivery. $\mathrm{n}=340$

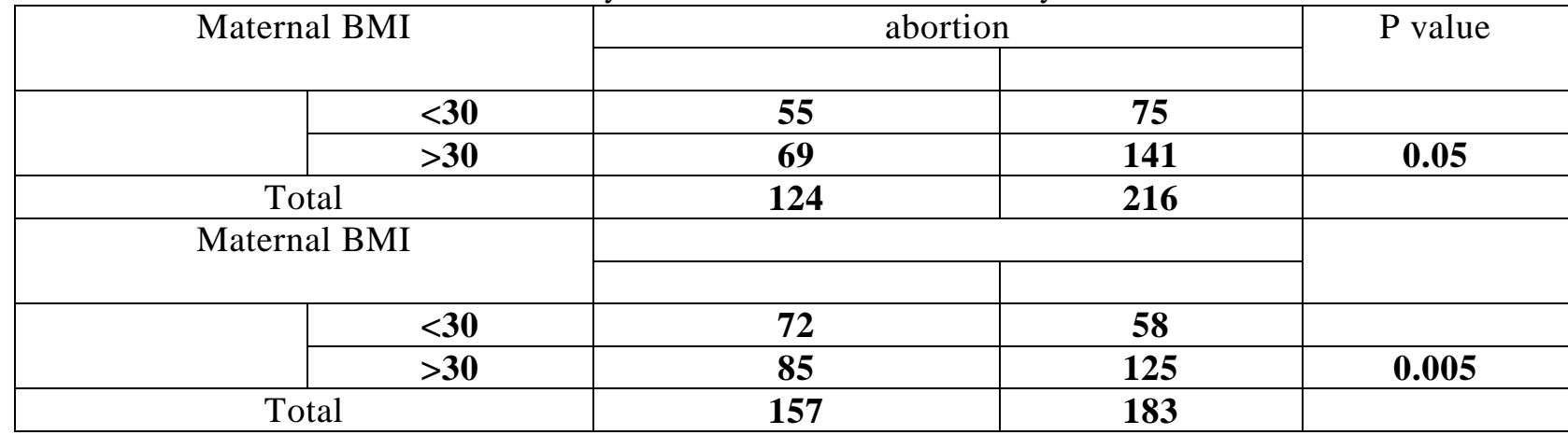

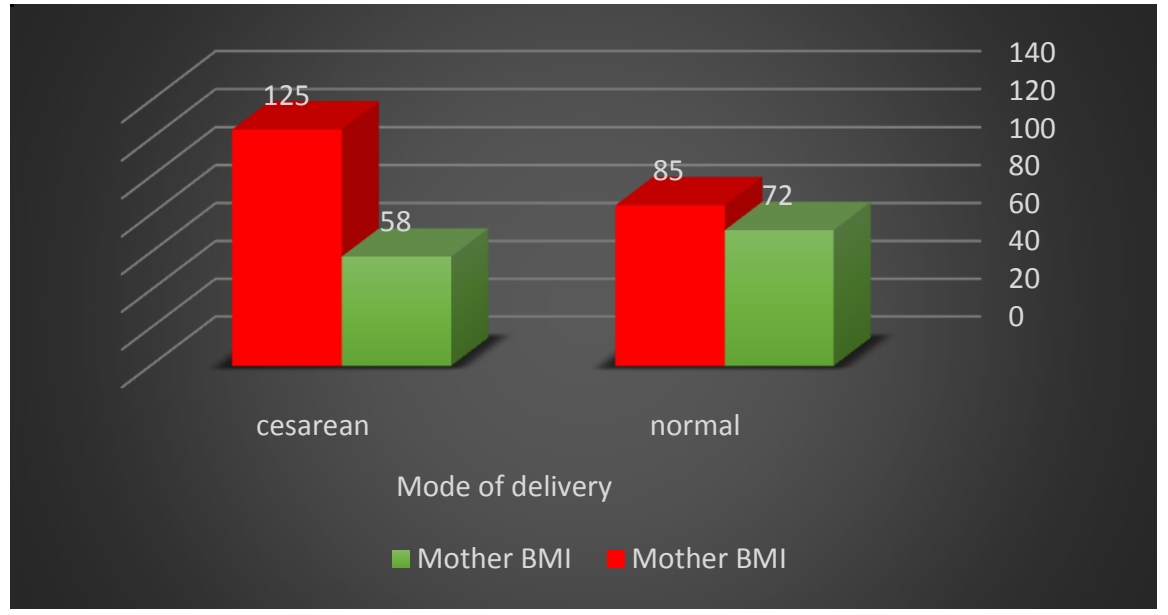

Figure 5: - Distribution of studied sample according tothe mode of delivery and maternal obesity.

As a secondary result of this study, 100 women who were obese and had a cesarean section were followed up for the purpose of delivery that Summarized in table 5

The highest proportion of obese women of the studied had no antenatal care during the pregnancy (32\%) and the lowest proportion of obese mother with cesarean section and don't have antenatal care as (18\%). this result showed 
there is no relationship between obese women that delivered by cesarean section and antenatal variables. Most of obese women that had complication after operation were double than don't have complication of cesarean section as (33\% and $17 \%$ respectively ) with significant association between obese women that delivered by cesarean section and wound infection, while the highest proportion of obese mothers had was normal birth weight (35\%) but without any significant association .regarding to operational time ,the result founded the obese women needed to more time for cesarean procedure than non-obese women . while the history of neonatal death founded in this result no any significant association with obese women that delivered by cesarean section. (table 5)

Table 5: - Distribution of study sample according to the material characteristic. N=100

\begin{tabular}{|c|c|c|c|c|}
\hline & & $\begin{array}{l}\text { Obese } \\
\mathrm{N}=50\end{array}$ & $\begin{array}{l}\text { Normal wt. } \\
\quad \mathrm{N}=50\end{array}$ & Pvalue \\
\hline \multirow[t]{2}{*}{ Antenatal care } & Yes & 18 & 23 & NS \\
\hline & No & 32 & 27 & \\
\hline \multirow[t]{2}{*}{ Time of operation } & $>35 \mathrm{~min}$ & 36 & 28 & 0.01 \\
\hline & $<35 \mathrm{~min}$ & 14 & 22 & \\
\hline \multirow[t]{2}{*}{ Birth weight (g) } & normal & 22 & 35 & NS \\
\hline & Over wt. & 28 & 15 & \\
\hline \multirow[t]{2}{*}{ wound Infection } & Yes & 33 & 26 & 0.01 \\
\hline & No & 17 & 24 & \\
\hline \multirow{2}{*}{$\begin{array}{l}\text { History of neonatal } \\
\text { death/stillbirth }\end{array}$} & Yes & 3 & 1 & NS \\
\hline & No & 47 & 49 & \\
\hline & & & & \\
\hline
\end{tabular}

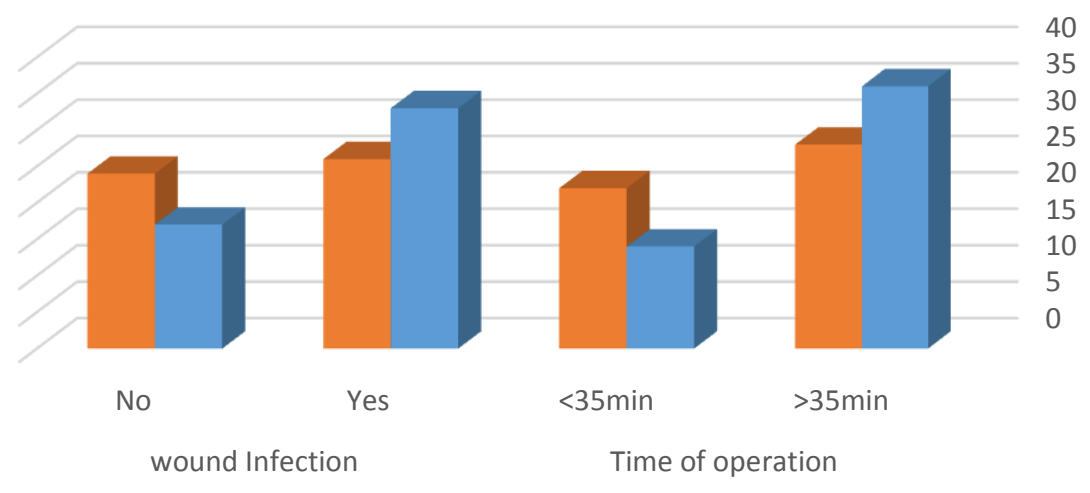

Figure 6: - Distribution study sample according to the time of operation and wound infection. $\mathrm{N}=100$ 


\section{Reference:-}

1. Organisation Mondiale de la santé. Département santé et développement, World Health Organisation Staff, World Health Organization, UNICEF. Global strategy for infant and young child feeding. World Health Organization; 2003.

2. McGuire W, Dyson L, Renfrew M. Maternal obesity: consequences for children, challenges for clinicians and carers. seminars in Fetal and Neonatal Medicine 2010 Apr 1 (Vol. 15, No. 2, pp. 108-112). WB Saunders.

3. Heslehurst N, Bell R, Rankin J. Tackling maternal obesity: the challenge for public health. Perspectives in public health. 2011 Jul 1.

4. Nuthalapaty FS, Rouse DJ. The impact of obesity on obstetrical practice and outcome. Clinical obstetrics and gynecology. 2004 Dec 1;47(4):898-913.

5. Freeman DJ. Effects of maternal obesity on fetal growth and body composition: implications for programming and future health. seminars in fetal and neonatal medicine 2010 Apr 1 (Vol. 15, No. 2, pp. 113-118). WB Saunders.

6. Bhattacharya S, Campbell DM, Liston WA, Bhattacharya S. Effect of body mass index on pregnancy outcomes in nulliparous women delivering singleton babies. BMC Public Health. 2007 Dec;7(1):168.

7. Denison FC, Chiswick C. Improving pregnancy outcome in obese women. Proceedings of the Nutrition Society. 2011 Nov;70(4):457-64.

8. Tabák AG, Herder C, Rathmann W, Brunner EJ, Kivimäki M. Prediabetes: a high-risk state for diabetes development. The Lancet. 2012 Jun 16;379(9833):2279-90.

9. Martin JA, Hamilton BE, Osterman MJ, Curtin SC, Mathews TJ. Births: final data for 2013.

10. Caughey AB, Cahill AG, Guise JM, Rouse DJ, American College of Obstetricians and Gynecologists. Safe prevention of the primary cesarean delivery. American journal of obstetrics and gynecology. 2014 Mar $1 ; 210(3): 179-93$.

11. Spong CY, Berghella V, Wenstrom KD, Mercer BM, Saade GR. Preventing the first cesarean delivery: summary of a Joint Eunice Kennedy Shriver national institute of child health and human development, society for maternal-fetal medicine, and American college of obstetricians and gynecologists' workshop. Obstetrics and Gynecology. 2012 Nov;120(5):1181.

12. Curtin SC, Gregory KD, Korst LM, Uddin SF. Maternal Morbidity for Vaginal and Cesarean Deliveries, According to Previous Cesarean History: New Data from the Birth Certificate, 2013. National vital statistics reports: from the Centers for Disease Control and Prevention, National Center for Health Statistics, National Vital Statistics System. 2015 May;64(4):1-3.

13. Watson WJ, George RJ, Welter S, Day D. High-risk obstetric patients. Maternal morbidity after cesareans. The Journal of reproductive medicine. 1997 May;42(5):267-70.

14. Al-Kubaisy W, Al-Rubaey M, Al-Naggar RA, Karim B, Noor NA. Maternal obesity and its relation with the cesarean section: A hospital-basedcross-sectional study in Iraq. BMC pregnancy and childbirth. 2014 Dec;14(1):235.

15. Al-Tawil NG, Abdulla MM, Abdul AA. Prevalence of and factors associated with overweight and obesity among a group of Iraqi women. Eastern Mediterranean health journal= La revue de Sante de la Mediterranee orientale= al-Majallah al-sihhiyah li-Sharq al-mutilator. 2007;13(2):420-9.

16. Davies GA, Maxwell C, McLeod L, Gagnon R, Basso M, Bos H, Delisle MF, Farine D, Hudon L, Menticoglou S, Mundle W. Obesity in Pregnancy: No. 239, February 2010.

17. Ting SM, Nair H, Ching I, Taheri S, Dasgupta I. Overweight, obesity and chronic kidney disease. Nephron Clinical Practice. 2009;112(3):c121-7.

18. Suleiman AA, Alboqai OK, Yasin N, El-Qudah JM, Bataineh MF, Obeidat BA. Prevalence of and factors associated with overweight and obesity among Jordan University students. Journal of Biological Sciences. 2009;9(7):738-45.

19. Must A, Spadano J, Coakley EH, Field AE, Colditz G, Dietz WH. The disease burden associated with overweight and obesity. Jama. 1999 Oct 27;282(16):1523-9.

20. Schutz Y, Woringer V. Obesity in Switzerland: a critical assessment of prevalence in children and adults. International Journal of Obesity. 2002 Aug 14;26(S2): S3.

21. Mauny F, Viel JF, Roubaix F, Ratsimandresy R, Sellin B. Blood pressure, body mass index and socioeconomic status in the urban population of Antananarivo (Madagascar). Annals of Tropical Medicine \& Parasitology. 2003 Sep 1;97(6):645-54.

22. Baeten JM, Bukusi EA, Lambe M. Pregnancy complications and outcomes among overweight and obese nulliparous women. American journal of public health. 2001 Mar;91(3):436. 
23. Scarborough P, Bhatnagar P, Wickramasinghe KK, Allender S, Foster C, Rayner M. The economic burden of ill health due to diet, physical inactivity, smoking, alcohol and obesity in the UK: an update to $2007-07$ NHS costs. Journal of public health. 2011 Dec 1;33(4):527-35.

24. Sarshar N, Khajavi AJ. The prevalence of obesity in females of 15-65 years of age in Gonabad, Iran. The Horizon of Medical Sciences. 2006 Sep 15;12(3):38-43.

25. Scott- Pillai RA, Spence D, Cardwell CR, Hunter A, Holmes VA. The impact of body mass index on maternal and neonatal outcomes: a retrospective study in a UK obstetric population, 2004 - 2011. BJOG: An International Journal of Obstetrics \& Gynaecology. 2013 Jul 1;120(8):932-9.

26. Saeidi M. Leisure-time physical activity and TV watching in relation to atherosclerosis risk factors in housewives and employees. Journal of Kermanshah University of Medical Sciences (J Kermanshah Univ Med Sci). 2005 Jan 4;8(4).

27. Kominiarek MA, VanVeldhuisen P, Hibbard J, Landy H, Haberman S, Learman L, Wilkins I, Bailit J, Branch W, Burkman R, Gonzalez-Quintero VH. The maternal body mass index: a strong association with a delivery route. American journal of obstetrics and gynecology. 2010 Sep 1;203(3):264-e1.

28. Tosson MM, Alhussaini TK: The impact of maternal obesity on pregnancy outcome at Assuit University Hospital. Ass Univ Bull Env Res 2005,8(2):1 - 11.

29. Enomoto K, Aoki S, Toma R, Fujiwara K, Sakamaki K, Hirahara F. Pregnancy outcomes based on prepregnancy body mass index in Japanese women. PLoS One. 2016 Jun 9;11(6): e0157081. 